\title{
L'aportació de Joaquim Gonzàlez Caturla a la rondallística valenciana
}

\author{
Vicent Vidal Lloret \\ Universitat d'Alacant \\ vicent.vidal@ua.es
}

\begin{abstract}
RESUM
Joaquim Gonzàlez Caturla és un dels primers autors valencians de la democràcia dedicat a la recopilació de rondalles. En aquest article s'analitza el conjunt de la seva producció rondallística $i$ es posa en relació amb el seu context a fi d'esbrinar-ne les característiques principals i valorar-ne l'aportació. Els seus dos reculls, Rondalles de l'Alacantí (1985) i Rondalles del Baix Vinalopó (1987), presenten unes característiques molt semblants que fan pensar en un lector model doble: el públic infantil-juvenil, pel format, el to i l'estil dels volums, $i$ un públic més especialitzat, pels pròlegs, les introduccions de l'autor i les notes d'interès lingüístic i folklòric. Això suposa un punt d'originalitat respecte dels rondallistes precedents $i$ remet a la doble vessant d'aquest autor: literat $i$ folklorista. L'altra originalitat que es destaca és el fet d'ésser l'únic folklorista que ha treballat sistemàticament les rondalles del Baix Vinalopó i el principal que ha tractat les de l'Alacantí. A pesar que Caturla disposava de diversos precedents al País Valencià, als anys vuitanta ell és un dels més importants per la quantitat i la qualitat de les rondalles que recull.
\end{abstract}

\section{PARAUles CLAU}

Joaquim Gonzàlez Caturla; literat-folklorista; rondalles; Rondalles de l'Alacantí; Rondalles del Baix Vinalopó

\begin{abstract}
Joaquim Gonzàlez Caturla is one of the most prominent Valencian writers to work on the compilation of folktales during the democratic period. The present article analyses the whole of his folktale production and relates it to its context with the aim of determining the main features of Caturla's work and his contribution to the discipline. His two compilations Rondalles de l'Alacanti (Folktales of Alacantí - 1985) and Rondalles del Baix Vinalopó (Folktales of Baix Vinalopó - 1987) have striking similarities that show that he had two readerships in mind: infants and children, due to the format, tone and style of the compilations; and a more specialised adult audience, due to the prologues, the writer's introductions and the notes on points of linguistic and folkloric interest. This demonstrates a certain originality with regard to previous folktale writers and highlights to the author's twin role of folktale writer and folklorist. Another point of originality is that he is the only folklorist to systematically study the folktales of Baix Vinalopo and is the leading authority on the folktales of Alicante. Although several others had trodden a similar path before him, during the I980s Caturla became one of the most important folklorists in Valencia owing to the quantity and the quality of the folktales that he compiled.
\end{abstract}

\section{KEYWORDS}

Joaquim Gonzàlez Caturla; folklorist and folktale writer; folktales; Rondalles de l'Alacantí; Rondalles del Baix Vinalopó

REBUT: I6.07.20I4 | ACCEPTAT: OI.09.20I4

Estudis de Literatura Oral Popular, núm. 4, 2OI5, I4I-I54 | DOI: IO.I7345/elop2OI5I4I-I54 ISSN: 20I4-7996 | http://revistes.urv.cat/index.php/elop 


\section{Introducció ${ }^{1}$}

Joaquim Gonzàlez Caturla (Alacant, I95I) és llicenciat en Filologia Hispànica, catedràtic a l'Institut Jorge Juan d'Alacant (ja jubilat), escriptor i activista cultural. Encara que s'ha consolidat com a narrador tant en literatura infantil i juvenil com en literatura per a adults i n'ha rebut diversos premis, va iniciar la carrera literària amb la publicació de dos reculls de narrativa popular: Rondalles de l'Alacantí (I985) i Rondalles del Baix Vinalopó (I987), tots dos publicats a través de l'Institut Alacantí de Cultura Juan Gil-Albert i amb els quals la institució enceta la col-lecció Tradició, que també publicarà el recull de rondalles de Pepa Guardiola (I988a) i que s'encarrega de:

recuperar una parte importante de nuestro patrimonio cultural como son las artes y costumbres tradicionales, muchas de las cuales sólo se conservan en la memoria de unos pocos, mientras otras sufren un proceso de transformación y desvirtuamiento, en algunos casos irrecuperable. Los temas son, pues, diversos: fiestas, música y canciones, cuentos y leyendas, artesanía, cultivos, utillaje... (Instituto de Estudios Juan Gil-Albert I984-I985: 59).

Com veurem, aquest caràcter «etnogràfic» de la col·lecció es correspon parcialment amb algunes característiques dels dos reculls de Caturla.

A banda dels dos reculls de rondalles, la publicació 5 rondalles amb Jordi Raül Verdú (2006), editada per l'Ajuntament d'Alacant per al II Salón del Libro Infantil Ilustrado, dins l'exposició «Animales en su tinta», és la reedició de cinc rondalles d'animals ja publicades anteriorment pels dos autors. Ben recentment també ha publicat La cara del moro d'Alacant (20I4), la versió literaturitzada de la llegenda del Benacantil a Alacant per a la campanya «Llegir en valencià» de la Fundació Bromera Per bé que no ha publicat cap més recull, ha fet diversos estudis i assaigs sobre rondallística (vegeu, per exemple, Gonzàlez Caturla I996, I997 i 20II), cosa que evidencia el seu interès manifest per aprofundir en la qüestió més enllà del mer recull.

Sense comptar l'obra d'Enric Valor, que considerem un autor de postguerrafranquisme perquè és l'etapa en què publica per primera vegada i en què veuen la llum la major part de les narracions, Joaquim G. Caturla és el quart autor en el temps d'un recull de rondalles al País Valencià després de la democràcia, i el primer circumscrit a la demarcació provincial d'Alacant. L'han precedit Marisa Lacuesta (I980), Josep Bataller Calderón (I98I, I986) i Tomàs Escuder (I983, I984), i immediatament el seguirà Pepa Guardiola (I988a i I988b), que també publica un recull a través de l'Institut Juan Gil-Albert.

A banda d'aquests reculls presentats com a únicament rondallístics, també es publiquen durant la democràcia diversos reculls folklòrics miscel-lanis en què, al costat de mostres de laliteratura oral popular com ara llegendes, cançons, etc., es poden trobar rondalles. En la mateixa dècada dels vuitanta, l'Institut Juan GilAlbert publica l'estudi antropològic de José Luis Bernabeu (Los límites simbólicos, I984), que va acompanyat d'un petit recull que inclou rondalles. La institució també es fa càrrec del recull d'Adolf Salvà a cura de Rafael Alemany; es publica

I. Aquest article forma part de l'activitat de recerca duta a terme a través del programa VALi+d finançat per la Conselleria d'Educació, Formació i Ocupació de la Generalitat Valenciana. 
l'any I988, però fou escrit durant els anys trenta del segle xx. A banda, també als anys vuitanta Edicions Aitana publica la primera edició facsímil de Còses de la meua tèrra de Francesc Martínez i Martínez: serà l'any del 75è aniversari del primer volum, el I987. ${ }^{2}$

Per tant, Joaquim Gonzàlez Caturla se situa en un context de plena embranzida dels reculls de rondalles valencianes. De fet, és un dels primers de la democràcia i el primer que comença a publicar durant aquesta etapa històrica al sud valencià sobre rondalles d'aquest entorn en format de recull rondallístic. Potser per això, o també per la qualitat i l'interès que desperten els seus reculls, tant Rondalles de l'Alacantí com Rondalles del Baix Vinalopó han estat reimpreses en diverses ocasions i fins i tot reeditades en l'editorial Aguaclara (Gonzàlez Caturla I998a i I998b) i en Marfil (Gonzàlez Caturla 2004 i 2005). El fet que l'edició i la publicació passe a mans privades en demostra l'èxit de lectors, ja que deixa de rebre el suport dels fons públics. En el moment de publicar-les se'n van fer presentacions, com la del 30 de maig de 1985 a càrrec del prologuista Emili Rodríguez i de Carmelina Sánchez-Cutillas (Institut Alacantí de Cultura Juan Gil-Albert I984-I985: 3I), ${ }^{3}$ i la crítica se'n va fer ressò i va rebre amb entusiasme aquest material (vegeu per exemple, les ressenyes d'Alemany [I987] i Balaguer [I988a i I988b]).

\section{Literat i folklorista}

Sovint s'ha destacat dels reculls de Caturla la fidelitat a l'oralitat, però caldria fer algunes matisacions en aquest punt: pensem que aquest autor no deixa de ser un «literat-folklorista», ${ }^{4}$ com intentarem demostrar.

No hi ha cap dubte que l'autor fa un gran treball en l'elaboració estilística de la llengua de les rondalles, que vol ser molt acostada al valencià meridional. Ell mateix aclareix que «aquest valencià meridional presenta tot un seguit de característiques i especificitats a nivell fonètic, morfosintàctic i lèxic», però la seva tasca en aquest nivell ha estat «recollir les expressions i modismes propis d'Alacant i la comarca» (I985: 20) en el primer recull, i es pot dir que en el segon actua semblantment. És a dir, en els seus reculls només hi tenen cabuda les «especificitats» de caràcter més lèxic, i encara explica que «he suprimit els castellanismes [...] i he corregit els dialectalismes i vulgarismes» (I985: 20), amb la qual cosa la llengua no se separa en excés de l'estàndard ni de la normativa. Hom podria oferir aquest acostament al valencià meridional com una raó per a la «fidelitat» a l'oralitat, però en aquest cas seria fidelitat a un model de llengua oral —i no del tot; A. M. Alcover («Jordi des Racó»), per exemple, hi aniria molt més lluny en la plasmació del dialecte en les Rondaies-, i no pas fidelitat a la manera com són contades les rondalles. A més, aquest acostament al valencià més genuí d'aquestes contrades és un dels elogis més recurrents que s'atribueixen a les rondalles i, en general, a la narrativa d'Enric Valor, de manera que Caturla no és innovador en aquest sentit, sinó que continua la pràctica de l'escriptor de Castalla. Aquests dos autors exer-

2. L'any del centenari (2OI2), l'Institut Juan Gil-Albert en torna a publicar una edició facsímil amb pròleg de Josep M. Baldaquí.

3. No deixa de ser interessant que Carmelina Sánchez-Cutillas, néta i biògrafa d'un dels nostres folkloristes més importants, Francesc Martínez i Martínez, prenga part d'alguna manera en aquest afer de recuperació del folklore valencià.

4. Aprofitem la denominació d'Oriol (2OII: 97). 
ceixen un equilibri entre la normativa i la vivesa del dialecte (en el cas de Valor, $c f$. Borja 20IO: 46).

Però és precisament en l'acarament Caturla-Valor quan es remarca la «fidelitat» del primer respecte de l'amplificació literària del segon. Quan s'ha volgut ponderar l'obra de Caturla, els estudiosos han tingut com a marc inevitable de referència la figura d'Enric Valor, el principal «literat-folklorista» de la postguerra valenciana, i és ben sabut que aquest autor, malgrat que respecta l'estructura argumental de les rondalles que recull, les «acoloreix» mitjançant llargues descripcions, digressions, diàlegs i, en fi, recreacions de tota mena, coherents amb el fil narratiu però totalment inventades. Valor, per això, i com apunta Carme Oriol (2OII: IO2), se situa en el pla «realista» dins del binomi abstracció/realisme de l'estil, segons la taxonomia que Josep Antoni Grimalt (2003) proposa per a l'anàlisi de les rondalles d'Alcover. En canvi, les rondalles de Caturla responen més aviat a un estil abstracte, caracteritzat pel predomini de l'acció de forma lineal, sense interferències ni digressions que retarden la narració. Segurament a això mateix es refereix Emili Rodríguez Bernabeu en el pròleg a les Rondalles de l'Alacantí quan indica que Caturla «s'ha ajustat tot el possible a la cadència popular de la narració» (I985: 9), que després desenvolupa:

- Condensació temàtica: relació de fets i no de situacions.

- Expressivitat lèxica.

- Brevetat d'exposició.

- Predomini de l'acció sobre la contemplació que comporta escassa aparició de descripcions paisatgístiques o humanes, deixant desdibuixades unes línies directrius (I985: IO).

Aquestes són, justament, característiques de l'abstracció i, com assenyala Grimalt (2003), és aquest l'estil més pròxim a la manera com són transmeses les rondalles en l'oralitat, mentre que el realisme és més propi del text literari escrit.

Això no vol dir que Caturla renuncie a fer literatura. És cert que, en la seva vessant de folklorista, ell mateix arreplega les rondalles directament de la tradició oral, possiblement amb enregistraments magnetofònics, ${ }^{5}$ sempre n'indica la procedència (el lloc d'arreplega) i en el recull del Baix Vinalopó, a més, ofereix un llistat amb els seus informants (1987: 22-23), ${ }^{6}$ encara que no n'explicita cap dada a banda de la població, i tampoc associa cap dels informants amb les rondalles. Ens trobaríem, doncs, davant d'un recull redactat a partir d'informants indeterminats (pel fet que es desconeix qui ha contat cada rondalla), i, a més, algunes rondalles han estat reconstruïdes a partir d'informants múltiples (cosa que sabem per les notes de l'autor o pels distints llocs d'arreplega d'una mateixa rondalla), és a dir, una mateixa rondalla pot haver estat reconstruïda a partir de dues o més versions, de manera que hi ha una tasca evident de literaturització i transformació del text

5. Aquesta dada no s'explicita enlloc dels dos reculls, però ho apunta Alemany (I987: 200) i el mateix autor ho ha dit públicament en alguna ocasió.

6. Tanmateix, caldria ser prudent en aquest punt: és possible que no totes les persones que figuren en aquest llistat siguen informants, perquè senzillament s'inclouen dins l'epígraf d'«agraïments», que adreça tant a les persones que li han contat les rondalles com a aquelles que l'han ajudat «acompanyant-me pels pobles, pels carrers, per les cases i presentant-me la gent que sabia aquestos [sic] contes» (I987: 22). 
original. A això cal afegir-hi petites descripcions, diàlegs, localitzacions espaciotemporals i modificacions de l'estil diverses: el respecte a la forma no és absolut, no hi ha transcripció, sinó redacció. De fet, en l'article que publica a Canelobre (I997) reflexiona sobre un conjunt de dificultats que ha de salvar l'escriptor quan passa el material oral a l'escrit literari, entre les quals hi ha el desinterès dels narradors orals per la descripció, la importància que hi pot tenir el gest i el parallenguatge, l'abundància d'interjeccions i la presència de vulgarismes, dialectalismes i barbarismes que, al seu parer, cal esmenar. És així que l'autor hi reconeix implícitament que la tasca del pas de l'oralitat a l'escriptura no pot ser un mer trasllat, sinó que hi calen una sèrie de modificacions. Per això, quan parlem del Caturla rondallista hem de tenir present que és un literat-folklorista.

Una de les raons que devia tenir en ment l'escriptor alacantí a l'hora de redactar les rondalles era el seu lector model. Al nostre parer, aquest lector model és doble, i respon a la doble vessant de literat i de folklorista de l'autor. Si atenem al to o a l'estil, ja s'ha comentat que és més aviat senzill i directe. A aquest estil cal sumar-hi la inclusió de fórmules d'inici i d'acabament de rondalles, com ara «Això diu que era» (I985: I47), «Això va ser o era» (I987: 77), «Heus aquí que una vegada hi havia» (I987: 85), «I conte acabat, per la ximenera se n'ha pujat al terrat» (I985: 50), «I conte acabat, per la ximenera s'ha escapat» (I985: I6O), «I catacric catacrac, el conte està acabat / i catacrac catacric, el conte ja està dit» (I987: II8), etc., i fins i tot l'ús d'apel-latius directes al lector infantil, de vegades de to moralitzant («I vosaltres ja sabeu, xiquets, que sempre heu de tenir consideració amb totes les persones, si no ningú no us voldrà», I985: 8I). Si a tot plegat s'hi afegeixen els paratextos (il·lustracions, coberta acolorida), és fàcil concloure que el lector model és, en principi, el públic infantil-juvenil. Aquest és el públic que busca el Caturla més literat, en el sentit que la part més creativa dels seus reculls sembla especialment adreçada a aquests lectors - a més que en general la rondalla és un gènere que sol buscar aquesta mena de receptors, amb les matisacions per subgèneres i edats que assenyalen, per exemple, Pujol (2009) o Valriu (20IO: 44I-445).

Hi ha, però, algunes qüestions que caldria no passar per alt: el pròleg erudit d'Emili Rodríguez Bernabeu a les Rondalles de l'Alacantí —i l'institucional de l'alcalde d'Elx, Manuel Rodríguez Macià, a les Rondalles del Baix Vinalopó-, la intenció del Gil-Albert en la creació de la col-lecció Tradició, ja citada, i les respectives introduccions de Caturla a cada recull i les seves notes amb informació lingüística o, sobretot, folklòrica, amb comparacions de les rondalles amb altres versions recollides o conegudes per l'autor, apunts sobre creences vinculades amb algun aspecte narrat, etc., fan pensar que Caturla s'adreça també a un públic adult que busca comentaris especialitzats. Aquest altre lector model està més relacionat amb la seva vessant de folklorista. L'autor presenta, per tant, una doble lectura de les rondalles: la lectura per entreteniment i la lectura acadèmica, i aquesta és una de les seves innovacions principals respecte dels literats-folkloristes precedents, generalment centrats a presentar un producte eminentment literari (el cas de Valor, sobretot). 


\section{L’aportació rondallística}

El primer que convé destacar de l'aportació de Caturla al corpus rondallístic valencià és el lloc d'arreplega de les rondalles. Dels 38 resultats que ofereix la base de dades RondCat ${ }^{7}$ per a rondalles recollides a l'Alacantí, 33 són de Caturla (un $86,84 \%$ ), mentre que els 32 resultats per a rondalles recollides al Baix Vinalopó es corresponen al Ioo\% amb les rondalles de Caturla. Aquesta localització és premeditada (Caturla fa un treball de camp específicament en aquestes dues comarques) i força equilibrada pel que fa als pobles de procedència. Sense Joaquim Gonzàlez Caturla, doncs, els valencians gairebé no disposaríem de rondalles arreplegades en aquestes dues comarques. La localització del seu treball, a més, coincideix amb la reivindicació del sud valencià que fa Caturla com a motivació dels seus treballs: d'una banda, per la desconnexió de les comarques del sud de la resta del País Valencià; de l'altra, per desmentir allò d' «En Alicante no hay nada» referit a la cultura pròpia (I985: I5) o a comentaris semblants referits al Baix Vinalopó. Estem d'acord, en aquest sentit, amb Anna i Maria Jesús Francés sobre la importància d'aquest treball de camp «en una zona on la situació del català és ben difícil per la pressió de forces externes diverses però que, en canvi, està farcida de tota una tradició transmesa oralment que identifica els parlants dins d'una mateixa comunitat lingüística i cultural» (2OI2: IO2).

Pel que fa les narracions pròpiament dites (l'adscripció genèrica, la catalogació internacional i la classificació que en fa l'autor), l'annex posa en relació les rondalles dels dos volums a partir dels gèneres que es diferencien als catàlegs rondallístics internacionals (ATU [Uther, 2004] o, en algun cas concret, AaTh [Aarne i Thompson, I96I]). Així, doncs, a partir d'aquests gèneres en la primera columna (rondalles d'animals, rondalles meravelloses, rondalles religioses, rondalles d'enginy o no meravelloses, contarelles, rondalles formulístiques i rondalles sense correspondència amb aquests índexs), en la segona columna es determina, per a cada rondalla, la catalogació corresponent seguint el RondCat; s'hi inclou la numeració que s'atorga, en aquesta base de dades, a rondalles que malgrat no tenir representació en els catàlegs internacionals, sí que tenen una presència significativa als territoris de parla catalana (numeració precedida per una C-). La tercera columna identifica el títol de cada rondalla segons Caturla, la quarta es correspon amb la classificació que en fa ell mateix («Animals personificats», «Prínceps, princeses, gegants i dimonis», «Temàtica fantàstica», «El Nostre Senyor, Sant Pere i la Mare de Déu», «Temàtica religiosa» i «Temàtica costumista») i a l'última s'assenyala a quin dels dos reculls pertany cada rondalla. Aquesta taula ens permet valorar amb precisió l'aportació real a la rondallística valenciana dins del marc comparatiu internacional i, alhora, ens permet fer una anàlisi aprofundida de la manera com Caturla concebé i s'aproximà críticament al material recollit.

Partint de les dades de l'annex, sobta, d'entrada, la quantitat de rondalles recollides: un total de 67. Per bé que Caturla és superat quantitativament per altres autors valencians com Francesc Martínez (70 narracions), Francesc Baldó (79), Rosabel i Mari Roig (90), M. Isabel Guardiola i Vicent Beltran (II8), Ester Limorti

7. La base de dades en línia RondCat permet la consulta d'informació bibliogràfica, catalogràfica i de contingut de les rondalles de tradició folklòrica recollides en llengua catalana en tota la seva àrea lingüística. El període considerat va des del I853, data d'edició del primer recull de rondalles catalanes, fins a l'actualitat. 
i Artur Quintana (I4I) o Josep Bataller (I79), només aquest últim se situaria, com s'ha vist, dins del context de publicació de Caturla, i d'aquestes I79 rondalles només n'hi ha 57 que es publiquen als anys vuitanta (Contalles populars valencianes I i II, I98I i I986). Des d'aquesta perspectiva, Joaquim Gonzàlez Caturla seria el rondallista valencià més prolífic dels anys vuitanta.

Deixant de banda els «miracles» o les llegendes sacres que recull sota l'epígraf «Miracles de sant Vicent Ferrer» en el primer recull (I985) i «Temàtica religiosa» en el segon (I987, que també inclou rondalles), la diversitat genèrica de les rondalles recollides és ben notable. Com es pot comprovar en les dues primeres columnes de l'annex, hi ha diverses mostres de rondalles d'animals, rondalles meravelloses, rondalles religioses, rondalles d'enginy, contarelles i rondalles formulístiques, a més de rondalles que no apareixen en aquests catàlegs classificatoris, algunes de les quals disposen d'altres variants reconegudes arreu del domini lingüístic català.

En cada recull, l'autor intenta una classificació pròpia dels materials: en el primer (I985) sembla una classificació més imbuïda pels personatges protagonistes, de manera que divideix la col·lecció en «Animals personificats», «Prínceps, princeses, bruixes, gegants i dimonis», «El Nostre Senyor, Sant Pere i la Mare de Déu» i, trencant la classificació per personatges, «Temàtica costumista». Tot i que no sempre és així, hi ha una correspondència força clara entre aquesta classificació i la respectiva de «Rondalles d'animals», «Rondalles meravelloses», «Rondalles religioses» $\mathrm{i}$ «Contarelles» dels catàlegs tipològics (compareu la primera i la quarta columna de l'annex), de manera que la classificació de Caturla és força reeixida i coherent. Aquesta classificació no s'acaba d'ajustar, però, a la que proposa Emili Rodríguez Bernabeu en el pròleg del primer recull:

Segons l'estructura i la temàtica, hi ha:

- Rondalles amb significació numinosa, amb una estructura generalment iniciàtica.

- Rondalles centrades sobre el tema de l'estrany o mutant.

- Rondalles religioses.

- Rondalles morals.

- Rondalles d'entreteniment (Gonzàlez Caturla I985: I2).

Malauradament, el prologuista no intenta assimilar a cap de les categories cap de les rondalles del recull ni intenta fer descripcions més detallades d'aquestes categories, de manera que, a diferència del parer d'Alemany (I987), que coincideix més amb Rodríguez Bernabeu que amb Caturla en la classificació de les rondalles, nosaltres ens avenim més amb el segon. En tot cas, potser perquè Caturla va creure més convenient un nou tipus de classificació o perquè va acceptar en part aquestes petites crítiques, l'any I987, en publicar les Rondalles del Baix Vinalopó, canviaria la classificació basada en el tipus de personatges en una divisió temàtica que, de tota manera, no sembla gaire diferent de la de I985 i, de fet, no segueix la proposta de Rodríguez. Així, ordenaria les rondalles segons la «Temàtica fantàstica» (que seria l'equivalent de l'anterior «Prínceps, princeses, bruixes, gegants i dimonis»), la «Temàtica religiosa» i, de nou, la «Temàtica costumista», mantenint, això sí, els «Animals personificats», focalitzant sobre els protagonistes abans que sobre la temàtica. Novament aquesta classificació en major o menor grau es 
correspon, respectivament, amb les «Rondalles meravelloses», «Rondalles religioses», «Contarelles» $\mathrm{i}$ «Rondalles d'animals» dels catàlegs internacionals (vegeu de nou la primera i la quarta columna de l'annex). ${ }^{8} \mathrm{Si}$ aquestes classificacions coincideixen en bona manera és gràcies al fet que els personatges, l'estructura i el to de cada gènere rondallístic tenen unes característiques determinades que Caturla va saber veure ja en el seu petit corpus - petit en comparació amb els corpus amb què treballen els catalogadors internacionals, que poden suggerir una classificació, per això, més precisa.

En comparació d'altres compiladors valencians de rondalles que el precedeixen, comptant-hi també els previs a la democràcia, si tenim com a referència la contribució al corpus rondallístic internacional seguint la classificació ATU, l'aportació de Joaquim Gonzàlez Caturla només és comparable als reculls de Josep Bataller Calderon; la resta d'autors precedents són bastant per davall del nombre de rondalles amb número ATU documentades. ${ }^{9}$ Seguint les dades del RondCat, els reculls de Caturla amplien sobretot la documentació de nous tipus de rondalles meravelloses i de contarelles, encara que també aporta tipus de rondalles d'animals, religioses, d'enginy i formulístiques que no s'havien documentat al País Valencià fins aleshores. Si es compara amb Bataller (I98I, I986), Caturla aporta més rondalles meravelloses, més rondalles religioses i més rondalles d'enginy, mentre que els reculls de Bataller incorporen més rondalles d'animals, del gegant beneit, formulístiques i contarelles que els de Caturla. A diferència d'autors com Enric Valor o Josep Bataller, Caturla, com Francesc Martínez, tendeix a presentar o a recollir les contarelles com a episodis solts, mentre que els altres dos generalment presenten aquesta mena de rondalles amb diversos tipus agrupats, cosa freqüent en aquest gènere.

Tot plegat demostra que l'alacantí ha estat un dels rondallistes valencians més importants dels anys vuitanta: perquè va aportar un bon nombre de materials narratius i perquè ho féu des d'una perspectiva força crítica i aproximada als estudis folklòrics i no únicament literària. Com assenyalen Anna i M. Jesús Francés, Caturla és, «juntament amb altres noms com Josep Bataller o Tomàs Escuder [...] el lligam entre l'obra de Valor i l'obra de nous folkloristes, més joves, que van sorgint al País Valencià» (2OI2: 95), però no solament en un sentit temporal. Joaquim Gonzàlez i Caturla pertany a la generació de folkloristes valencians que, als anys vuitanta, impulsats per les possibilitats educatives de la literatura popular

8. En concret, de les rondalles que l'autor classifica sota l'epígraf «Animals personificats», 8 de I3, es corresponen amb les «Rondalles d'animals» dels catàlegs internacionals, i 2 no es corresponen amb cap número ATU; de les que per a Caturla són rondalles de «Prínceps, princeses, gegants i dimonis» o de «Temàtica fantàstica», I2 de 2I es corresponen amb les anomenades «Rondalles meravelloses», i 4 no tenen número ATU; de les que classifica amb el títol «El Nostre Senyor, sant Pere i la Mare de Déu» i «Temàtica religiosa», 5 de 9 es correspondrien amb les «Rondalles religioses» dels catàlegs internacionals, i 3 no tenen número ATU; i de les que anomena rondalles de «Temàtica costumista», I5 de 22 es corresponen amb el que coneixem per «Contarelles» i 3 no tenen número ATU. Com es pot observar arran d'aquesta comparativa, el criteri de Caturla és força assenyat i es correspon en gran manera amb els catàlegs internacionals, a pesar que no demostra conèixer-los en cap moment.

9. Encara que la quantitat de relats que el RondCat documenta de Francesc Martínez és sensiblement major (70 resultats per a Martínez enfront dels 67 per a Caturla), la majoria de les narracions de Martínez no tenen assignat un número ATU, segurament perquè, en molts casos, aquestes narracions no són rondalles pròpiament dites. 
i seguint el model que els proporcionava la tasca d'Enric Valor, van contribuir significativament a la recopilació de rondalles des d'una òptica diferent dels autors precedents: és la generació que fa de baula entre un folklore més purament literari i un de més científic com el que trobarem en autors valencians posteriors com Ester Limorti i Artur Quintana (I998) o M. Isabel Guardiola i Vicent Beltran (2005), que opten per una transcripció fidel a l'oralitat i per metodologies pròpies d'aquest camp d'estudi.

\section{Conclusions}

En síntesi, Joaquim Gonzàlez i Caturla és un literat-folklorista que publica en un context en què els reculls de rondalles comencen a florir amb noms com Josep Bataller, Tomàs Escuder o Pepa Guardiola, a banda dels reculls miscel.lanis de folklore que aniran apareixent des dels anys vuitanta fins a l'actualitat i que també inclouran rondalles. Pertany a una generació de folkloristes que, seguint l'empremta d'Enric Valor i aprofitant l'interès didàctic de l'etnopoètica, recullen i publiquen materials folklòrics i omplen el buit d'arreplegues que tenien els valencians fins llavors.

Els seus dos reculls, Rondalles de l'Alacantí (1985) i Rondalles del Baix Vinalopó (I987), semblen adreçats a un doble lector model: l'infantil-juvenil, pel to, l'estil i el format dels volums, i un de més acadèmic o especialitzat a qui s'adrecen els pròlegs, les introduccions de l'autor i les notes d'interès lingüístic i sobretot folklòric, cosa que constitueix un punt d'originalitat respecte dels rondallistes precedents. L'aportació al corpus rondallístic valencià és realment substancial, en tant que és l'únic folklorista que ha treballat sistemàticament les rondalles del Baix Vinalopó i el principal que ha tractat les de l'Alacantí. A pesar que Caturla té diversos precedents valencians recol-lectors de rondalles, als anys vuitanta només Josep Bataller s'hi pot comparar en nombre de rondalles recollides. La contribució de Caturla és, doncs, significativa per la varietat dels gèneres que recull, i destaca, sobretot, en les rondalles meravelloses i en les contarelles.

Dins de l'etapa històrica dels folkloristes que comencen a publicar en democràcia, Caturla figura al costat dels qui han estat una baula entre el model d'Enric Valor, que el tenen com a referent i segueixen en alguns trets de l'estil i la literaturització, i el model més pròpiament folklòric i acadèmic de respecte a la narració tal com és contada pels informants. En aquest context, Caturla és un dels noms capdavanters: és, sens dubte, un dels autors més rellevants i el més destacat, si més no, dels rondallistes de la demarcació d'Alacant.

\section{Referències bibliogràfiques}

AARne, Antti; Stith Thompson (AaTh) (I96I): The types of the folktale: a classification and bibliography. Folklore Fellows' Comunication, I84. Hèlsinki: Suomalainen Tiedeakatemia.

Alemany, Rafael (I987): «[Ressenya de] Joaquim Gonzàlez i Caturla: Rondalles de l'Alacantí, Institut d'Estudis Juan Gil-Albert, za edició, Alacant, I985, 2I8 pàgines». L'Espill 23-24 (gener I987): I99-20I. 
BALAgUer, Enric (I988a): «[Ressenya de] Joaquim Gonzàlez i Caturla: Rondalles del Baix Vinalopó, Institut d'Estudis Juan Gil-Albert, Alacant, I987». L'Espill 26 (febrer I988): II5-II7.

— (I988b): «De la tradició oral a la literatura [Ressenya de Joaquim Gonzàlez i Caturla: Rondalles del Baix Vinalopó, Institut d'Estudis Juan Gil-Albert, Alacant, I987]». El temps I92 (any V) (22-27 de febrer, I988): 78.

BATALlER, Josep (I98I): Contalles populars valencianes, I. València: Institució Alfons el Magnànim.

- (I986a): Contalles populars valencianes, II. València: Institució Alfons el Magnànim / Institució Valenciana d'Estudis i Investigacions.

BernabeU, José Luis (I984): Los límites simbólicos. Hombres de la Foia de Castalla y el Vall de Xixona. Alacant: Institut d'Estudis Alacantins / Diputació Provincial d'Alacant.

BORJA, Joan (2OIO): «L'obra rondallística: la literaturització dels relats tradicionals orals». Dins Verònica CANTó; Vicent Brotons; Òscar PÉrez (eds.): Enric Valor. El Valor de les paraules. València: Acadèmia Valenciana de la llengua, p. 46-6o.

Escuder, Tomàs (1983): Contalles. Castelló: Caja de Ahorros y Monte de Piedad de Castellón.

- (I984): Un dia, la por. Vinaròs: Associació Cultural Alambor.

FrAncÉS, M. Jesús; Anna FrAnCÉS (2OI2): «La recerca folklòrica: Joaquim González i Caturla i les seues rondalles». Dins Josep Temporal; Laura VILLALBA (eds.): La recerca folklòrica: persones $i$ institucions. Alacant: Institut Alacantí de Cultura Juan Gil-Albert / Arxiu de Tradicions de l'Alguer / Grup d'Estudis Etnopoètics de la Societat Catalana de Llengua i Literatura, filial de l'Institut d'Estudis Catalans, p. 93-IO3.

GonzÀlez I CATURla, Joaquim (I985): Rondalles de l'Alacantí. Pròleg d'Emili Rodríguez-Bernabeu. Alacant: Institut d'Estudis Juan Gil-Albert.

- (I987): Rondalles del Baix Vinalopó. Alacant: Institut d'Estudis Juan Gil-Albert.

- (I996): «Del text oral al text escrit. Algunes especificitats de les rondalles meridionals». Dins Simposi d'Estudi i festa Enric Valor. Actes. Alacant: Excma. Diputació d'Alacant, p. 27-34.

- (I997): «Les rondalles d'Enric Valor». Canelobre 37-38: 4I-48.

- (I998a): Rondalles de l'Alacantí. Pròleg d'Emili Rodríguez-Bernabeu. Alacant: Aguaclara.

- (I998b): Rondalles del Baix Vinalopó. Alacant: Aguaclara.

- (2004): Rondalles de l'Alacantí. Alcoi: Marfil.

- (2005): Rondalles del Baix Vinalopó. Alcoi: Marfil.

— (2OII): «Enric Valor: el valor d'un idioma en perill». El Salt núm. 26 (primavera 2OII): 32-35.

- (20I4): La cara del moro d'Alacant. Alzira: Fundació Bromera.

GonzÀlez I CATURla, Joaquim; Jordi Raül Verdú (2006): 5 Rondalles. Alacant: Ajuntament d'Alacant. 
GRIMALT, Josep A. (2003): «Les rondalles de mossèn Alcover, entre el realisme i l'estil abstracte». Dins Jaume GuISCAFrè; Antoni PiCornell (eds.): Actes del Congrés Internacional Antoni M. Alcover. Barcelona: Publicacions de l'Abadia de Montserrat, p. 563-579.

GuARdiola, M. Isabel; Vicent BeLtran (2005): Bolulla la caramulla. Cultura popular i llengua d'un poble de la Marina. Sant Joan d'Alacant: Institut Alacantí de Cultura Juan Gil-Albert.

GuARdiola, Pepa (I988a): Contes de riu-rau (recull de contes populars de la Marina Alta). Xàbia: Institut d'Estudis Juan Gil-Albert / Ajuntament de Xàbia.

— (I988b): El llop i la cogullada. Xàbia: Ajuntament de Xàbia.

InSTITUTO DE Estudios JuAn GIL-AlberT (I984-85): Memoria. Instituto de Estudios Juan Gil-Albert (1984-I985). Alacant: Instituto de Estudios Juan Gil-Albert.

MARTínez, Francesc (20I2 [I9I2-47]): Còses de la meua tèrra (la Marina), 3 vols. Alacant: Institut Alacantí de Cultura Juan Gil-Albert.

LACuesta, Marisa (I980): Recollim contes populars. Sueca: Federació d'Entitats Culturals del País Valencià.

LimorTI, Ester; Artur QUINTANA (I998): El Carxe. Recull de literatura popular valenciana de Múrcia. Elx: Institut de Cultura Juan Gil-Albert / Diputació Provincial d'Alacant.

OrIOL, Carme (2OII): «Les rondalles d'Enric Valor en el marc de la rondallística catalana». Dins Gemma LluCH; Josep M. BALDAQUí (eds.): Nova reflexió sobre l'obra d'Enric Valor. Alacant: Institut Interuniversitari de Filologia Valenciana, p. 95-I09.

Pujol, Josep M. (2009): «La rondalla (o com voldríem que fos la vida)». Escola Catalana 457 (març-abril 2009): I2-I4 [Inclòs dins Això era i no era. Obra folklòrica de Josep M. Pujol. Edició a cura de Carme Oriol i Emili SAMPer. Tarragona: Publicacions URV, 2OI3, p. 397-399].

RondCat: cercador de la rondalla catalana, Arxiu de Folklore, Departament de Filologia Catalana de la Universitat Rovira i Virgili <http://rondcat. arxiudefolklore.cat $>$ [data de consulta: agost de 20I5].

SAlVÀ, Adolf (I988): De la Marina i muntanya (folklore). Edició a cura de Rafael Alemany. Alacant: Institut d'Estudis Juan Gil-Albert / Ajuntament de Callosa d'en Sarrià.

SAMPer Prunera, Emili (20I3): "Cels Gomis i Mestre: Biografia i narrativa folklòrica». Tesi doctoral dirigida per la Dra. Carme OrIOL CARAzo i el Dr. Magí Sunyer Molné. Tarragona: Universitat Rovira i Virgili, Departament de Filologia Catalana. Disponible en línia: <http://hdl.handle.net/Io803/IIIo95> [data de consulta: agost de 20I3].

UTHER, Hans-Jörg (ATU) (2004): The types of international folktales. A classification and bibliography. Based on the system of Antti Aarne and Stith Thompson. 3 vols. Folklore Fellows' Comunication, 284, 285, 286. Hèlsinki: Suomalainen Tiedeakatemia.

VALRIU, Caterina (20IO): Imaginari compartit. Estudis sobre literatura infantil i juvenil. Montcada i Reixac: Publicacions de l'Abadia de Montserrat / Edicions UIB / Institut d'Estudis Baleàrics. 


\section{Annex}

\section{Les rondalles de Joaquim Gonzàlez i Caturla ${ }^{10}$}

\begin{tabular}{|c|c|c|c|c|}
\hline $\begin{array}{l}\text { Gènere } \\
\text { (segons } \\
\text { AaTh i ATU) }\end{array}$ & $\begin{array}{l}\text { Catalogació } \\
\text { (ATU, AaTh } \\
\text { i RondCat)' }\end{array}$ & $\begin{array}{l}\text { Títol de la rondalla } \\
\text { (segons J. G. Caturla) }\end{array}$ & $\begin{array}{l}\text { Classificació } \\
\text { de l'autor }\end{array}$ & Recull \\
\hline \multirow{7}{*}{$\begin{array}{l}\text { Rondalles } \\
\text { d'animals }\end{array}$} & 3 & «La raboseta i el rabosot» & \multirow{7}{*}{ Animals personificats } & \multirow{2}{*}{$\mathrm{BV}^{2}$} \\
\hline & 105 & «La raboseta i el gat» & & \\
\hline & AaTh 112 & «El gat i la rateta» & & \multirow{8}{*}{$A^{3}$} \\
\hline & $122 \mathrm{~A}$ & «L'astúcia de la comare rabosa» & & \\
\hline & 123124 & «Raboseta, obri!» & & \\
\hline & 130 & «L'ase, el gos, el gat i el gall» & & \\
\hline & 250 & $\begin{array}{l}\text { «La carrera entre la balena i } \\
\text { l'esparralló» }\end{array}$ & & \\
\hline \multirow{15}{*}{$\begin{array}{l}\text { Rondalles } \\
\text { meravelloses }\end{array}$} & 302 & «Joanet el pescador» & \multirow{3}{*}{$\begin{array}{l}\text { Prínceps, princeses, } \\
\text { gegants i dimonis }\end{array}$} & \\
\hline & $311 B^{*}$ & «Les set germanes» & & \\
\hline & 332 & «La metgessa del dimoni» & & \\
\hline & $\begin{array}{l}\text { AaTh } 363365 \\
\text { o } 366329-330\end{array}$ & «Els Garrofers del dimoni» & \multirow[t]{2}{*}{ Temàtica fantàstica } & \multirow[t]{2}{*}{ BV } \\
\hline & 366 & «Marieta i el mort» & & \\
\hline & $425 \mathrm{C}$ & «La rosa de l'amor» & \multirow{3}{*}{$\begin{array}{l}\text { Prínceps, princeses, } \\
\text { gegants i dimonis }\end{array}$} & \multirow{3}{*}{ A } \\
\hline & 451 & «Els set germans encantats» & & \\
\hline & 480 & «L'estreleta d'or» & & \\
\hline & $510 \mathrm{~A}$ & «Granereta de pastera» & \multirow[b]{2}{*}{ Temàtica fantàstica } & \multirow[b]{2}{*}{ BV } \\
\hline & 531408 & $\begin{array}{l}\text { «El príncep aventurer i l'amor de les } \\
\text { tres taronges» }\end{array}$ & & \\
\hline & 555 & «L'ambició de Francesqueta» & $\begin{array}{l}\text { El Nostre Senyor, sant } \\
\text { Pere i la Mare de Déu }\end{array}$ & \multirow[t]{2}{*}{ A } \\
\hline & 563 & «Les faves del cel» & Temàtica costumista & \\
\hline & AaTh 565 & «El dia del miracle» & Temàtica fantàstica & BV \\
\hline & $650 \mathrm{~A}$ & «El forçut de Xixona» & $\begin{array}{l}\text { Prínceps, princeses, } \\
\text { gegants i dimonis }\end{array}$ & A \\
\hline & 700 & «Joanet Pelitxilico» & \multirow{2}{*}{ Temàtica costumista } & BV \\
\hline \multirow{9}{*}{$\begin{array}{l}\text { Rondalles } \\
\text { religioses }\end{array}$} & $750 \mathrm{~A}$ & «El cullerot» & & \multirow{4}{*}{ A } \\
\hline & AaTh 774 & «El Nostre Senyor tot ho veu» & \multirow{3}{*}{$\begin{array}{l}\text { El Nostre Senyor, sant } \\
\text { Pere i la Mare de Déu }\end{array}$} & \\
\hline & AaTh 774 & $\begin{array}{l}\text { «Per què els pinyols dels dàtils tenen } \\
\text { una o?» }\end{array}$ & & \\
\hline & AaTh 774 & $\begin{array}{l}\text { «Per què el gall té dues taques } \\
\text { negres?» }\end{array}$ & & \\
\hline & AaTh 774 & «Sant Pere i la mitja taronja» & Temàtica religiosa & BV \\
\hline & AaTh 758 & «Per què hi ha rics i pobres» & Temàtica costumista & \\
\hline & 780 & «Peret i Margarideta» & $\begin{array}{l}\text { Prínceps, princeses, } \\
\text { gegants i dimonis }\end{array}$ & A \\
\hline & 780 & «La flor del lilolà. La flor del Iliri blau» & Temàtica fantàstica & BV \\
\hline & 791 & «Les garrotades de sant Pere» & \begin{tabular}{|l|} 
El Nostre Senyor, sant \\
Pere i la Mare de Déu
\end{tabular} & A \\
\hline
\end{tabular}

Io. Deixem de banda els «miracles» o llegendes sacres que inclou Caturla en els seus reculls: els «Miracles de sant Vicent Ferrer» («Miracle del burro», «Miracle del mocador», «Sequet però sanet») (Gonzàlez i Caturla I985) i «La Mare de Déu del Loreto de Santa Pola», «La Mare de Déu de l'Assumpció» i «Miracle de Sant Francesc» (Gonzàlez i Caturla 1987). 


\begin{tabular}{|c|c|c|c|c|}
\hline $\begin{array}{l}\text { Gènere } \\
\text { (segons } \\
\text { AaTh i ATU) }\end{array}$ & $\begin{array}{l}\text { Catalogació } \\
\text { (ATU, AaTh } \\
\text { i RondCat)' }\end{array}$ & $\begin{array}{l}\text { Títol de la rondalla } \\
\text { (segons J. G. Caturla) }\end{array}$ & $\begin{array}{l}\text { Classificació } \\
\text { de l'autor }\end{array}$ & Recull \\
\hline \multirow{3}{*}{$\begin{array}{l}\text { Rondalles } \\
\text { d'enginy o } \\
\text { rondalles no } \\
\text { meravelloses }\end{array}$} & 851 & «L'endevinalla de la princesa» & Temàtica fantàstica & BV \\
\hline & 879 & «El conte de l'alfabegueta» & $\begin{array}{l}\text { Prínceps, princeses, } \\
\text { gegants i dimonis }\end{array}$ & A \\
\hline & $910 \mathrm{~B}$ & «Els tres consells» & Temàtica fantàstica & \multirow{2}{*}{ BV } \\
\hline \multirow{15}{*}{ Contarelles } & AaTh 1322 & «Joanet i els pinyols» & \multirow{16}{*}{ Temàtica costumista } & \\
\hline & 1350 & «Pere Joano» & & \multirow{3}{*}{ A } \\
\hline & 1370 & «El gat a l'esquena» & & \\
\hline & $1381 \mathrm{~A}$ & «Un lluç enmig del bancal» & & \\
\hline & 13871218 & «Peret? Mare, coc!» & & \multirow{7}{*}{ BV } \\
\hline & 1406 & «Els enganys de les dones» & & \\
\hline & AaTh $1419 \mathrm{H}$ & «El sangandongo» & & \\
\hline & $1562 \mathrm{~A}$ & «La xirindanga» & & \\
\hline & $1628^{*}$ & «El seminarista famolenc» & & \\
\hline & 1682 & «El burro del tio Pauet» & & \\
\hline & 1689 & «Conte del mallorquí» & & \\
\hline & 1689A & «Les bacores del rei» & & \multirow{3}{*}{ A } \\
\hline & 1696 & «Les comandes de Peret» & & \\
\hline & 1730 & «Tico-Taco o el capellà que va fer oli» & & \\
\hline & $\begin{array}{l}\text { AaTh } 1730 \text { o } \\
1419 \mathrm{H}\end{array}$ & «La dona i el capellà» & & \multirow[t]{2}{*}{ BV } \\
\hline \multirow{4}{*}{$\begin{array}{l}\text { Rondalles } \\
\text { formulístiques }\end{array}$} & 2022 & «El pipiritxó» & & \\
\hline & 2031 & «Conte de la formigueta» & \multirow{3}{*}{ Animals personificats } & A \\
\hline & AaTh 2271 & «L'home i el gos. El conte dels ànecs» [l] & & \multirow{8}{*}{ BV } \\
\hline & 2300 & «L'home i el gos. El conte dels ànecs» [III] & & \\
\hline \multirow{12}{*}{$\begin{array}{l}\text { Sense } \\
\text { correspondència } \\
\text { amb ATU o } \\
\text { AaTh }\end{array}$} & C-027 & «Com parlen a Guardamar?» & Temàtica costumista & \\
\hline & C-029 & «Per què la mula no té fills» & \multirow{3}{*}{ Temàtica religiosa } & \\
\hline & C-042 (?) ${ }^{4}$ & «Per què la figuera fa dues collites?» & & \\
\hline & C-042 & «Per què la figuera fa tres collites?» & & \\
\hline & C-098 C- $100^{5}$ & «Les bruixes de Tabarca» & \multirow{2}{*}{ Temàtica fantàstica } & \\
\hline & & «El tresor de la muralla» & & \\
\hline & & «La vareta de les tres virtuts» & \multirow{2}{*}{$\begin{array}{l}\text { Prínceps, princeses, } \\
\text { bruixes, gegants i } \\
\text { dimonis }\end{array}$} & \multirow{3}{*}{ A } \\
\hline & & «Ric, el tio Roc» & & \\
\hline & & «L'aranya, la cigala i l'abella» & \multirow{2}{*}{ Animals personificats } & \\
\hline & & «L'home i el gos. El conte dels ànecs» $[11]^{6}$ & & \multirow{2}{*}{ BV } \\
\hline & & «Seculorum, saculera» & \multirow{2}{*}{ Temàtica costumista } & \\
\hline & & «L'home que sabia totes les cançons» & & A \\
\hline
\end{tabular}




\section{Vicent Vidal Lloret}

\section{Notes del quadre}

I. Seguim les dades catalogràfiques del RondCat i, sempre que no s'indique el contrari, els números es correspondran amb el catàleg d'ATU. Les rondalles catalogades segons l'antic sistema Aarne-Thompson (AaTh; Aarne i Thompson, 196I) es corresponen amb la catalogació d'altres autors segons el que es pot comprovar en l'apartat reservat a les notes en la fitxa bibliogràfica de cada rondalla del RondCat. Aquesta base de dades també inclou alguns tipus que no formen part del catàleg internacional d'Aarne-Thompson-Uther però tenen una presència significativa als territoris de parla catalana. Són els que van precedits per una C-.

2. Rondalles del Baix Vinalopó (I987).

3. Rondalles de l'Alacantí (1985).

4. Al RondCat, tant la narració «Per què la figuera fa dues collites?» com «Per què la figuera fa tres collites?» apareixen catalogades amb el mateix número (C-O42), però presenten arguments essencialment diferents. Mentre el relat amb el títol «Per què la figuera fa tres collites?» sí que es correspondria amb el tipus resumit («La fruita que més agradava a sant Pere»), en què Sant Pere, per estalviar-se la fama de borratxo, respon al Nostre Senyor que la fruita que més li agrada és la figa en lloc del raïm, i per això el Nostre Senyor li concedeix tres collites, el relat «Per què la figuera fa dues collites» explica com Judes es va suïcidar penjant-se d'una figuera i aquesta, avergonyida, renuncià al seu primer fruit, la bacora, i en tragué un de més durador a finals d'estiu, la figa.

5. Encara que aquests números del catàleg del RondCat no formen part de la versió pública de la base de dades en el moment en què escrivim aquest article (i no s'hi cataloga de cap manera aquesta rondalla de Caturla), és ben probable que hi acaben formant part gràcies a les propostes de la tesi doctoral d'Emili Samper (20I3: 309, 3I9). Així cataloga ell mateix la versió de Caturla.

6. Caturla inclou tres narracions diferents sota el títol «L'home i el gos. El conte dels ànecs» que, a pesar que formen part de l'epígraf d'«animals personificats», en realitat no en contenen cap, si bé és cert que els animals - no personificats- hi tenen un paper important. En realitat, es tracta de rondalles formulístiques i rondalles broma o rondalles sorpresa. 